\title{
Poly (D,L-lactide-co-glycolide) nanoparticles: Uptake by epithelial cells and cytotoxicity
}

\author{
L. A. Nkabinde ${ }^{1}$, L. N. N. Shoba-Zikhali ${ }^{1}$, B. Semete-Makokotlela ${ }^{2}$, L. Kalombo $^{2}$, H. Swai ${ }^{2}$, \\ A. Grobler $^{3}$, J. H. Hamman ${ }^{4} 5^{*}$ \\ ${ }^{1}$ Council for Scientific and Industrial Research, Biosciences, P.O. Box 395, 0001 Pretoria, South Africa \\ ${ }^{2}$ Council for Scientific and Industrial Research, Material Science and Manufacturing, Polymers and Bioceramics, \\ P.O. Box 395, 0001 Pretoria, South Africa \\ ${ }^{3}$ Pre-clinical Platform for Drug Development, North-West University, Private Bag X6001, 2520 Potchefstroom, \\ South Africa \\ ${ }^{4}$ Centre of Excellence for Pharmaceutical Sciences, North-West University, Private Bag X6001, 2520 Potchefstroom, \\ South Africa \\ ${ }^{5}$ Tshwane University of Technology, Department of Pharmaceutical Sciences, Private Bag X680, 0001 Pretoria, \\ South Africa
}

Received 7 August 2013; accepted in revised form 29 October 2013

\begin{abstract}
Nanoparticles as drug delivery systems offer benefits such as protection of the encapsulated drug against degradation, site-specific targeting and prolonged blood circulation times. The aim of this study was to investigate nanoparticle uptake into Caco-2 cell monolayers, their co-localization within the lysosomal compartment and their cytotoxicity in different cell lines. Rhodamine-6G labelled poly(D,L-lactide-co-glycolide) (PLGA) nanoparticles were prepared by a double emulsion solvent evaporation freeze-drying method. Uptake and co-localisation of PLGA nanoparticles in lysosomes were visualized by confocal laser scanning microscopy. The cytotoxicity of the nanoparticles was evaluated on different mammalian cells lines by means of Trypan blue exclusion and the MTS assay. The PLGA nanoparticles accumulated in the intercellular spaces of Caco-2 cell monolayers, but were also taken up transcellularly into the Caco-2 cells and partially co-localized within the lysosomal compartment indicating involvement of endocytosis during uptake. PLGA nanoparticles did not show cytotoxic effects in all three cell lines. Intact PLGA nanoparticles are therefore capable of moving across epithelial cell membranes partly by means of endocytosis without causing cytotoxic effects.
\end{abstract}

Keywords: biocompatible polymers, Caco-2 cells, cellular uptake, cytotoxicity, PLGA nanoparticles

\section{Introduction}

Nanoparticles have received a lot of interest as carriers for drug molecules via the oral route of drug administration because they are capable to overcome certain drug delivery challenges. Nanoparticles can encapsulate a large variety of hydrophilic and hydrophobic drugs $[1,2]$, enhance the bioavailability of certain drugs, increase the residence time and can target specific tissues [3]. Nanoparticles also provide protection to drug molecules against enzy- matic and hydrolytic degradation in the gastrointestinal tract [4] and can be directly taken up by enterocytes $[5,6]$. Biomaterials that have been used as drug carriers include natural polymers (e.g. chitosan, cellulose, hydroxyapatite) and synthetic polymers (e.g. $\alpha$-hydroxy acids such as poly(glycolic acid), poly(Llactic acid) and poly(D,L-lactide-co-glycolide)) [7, 8]. The physical properties of nanoparticles prepared from natural polymers are less predictable and concerns were raised regarding their stability

\footnotetext{
${ }^{*}$ Corresponding author, e-mail: sias.hamman@nwu.ac.za

(C) BME-PT
} 
and immunogenicity. Synthetic polymers are therefore more favoured in some cases for drug delivery system development [9].

Poly(D,L-lactide-co-glycolide) (PLGA) is one of the most suitable polymers for bio-applications amongst the synthetic polymers owing to its favorable biodegradable and biocompatibility characteristics which has been proven over the past three decades [10]. This co-polymer degrades to compounds that are found in the human body (i.e. lactic and glycolic acid) and is safe for human consumption [11], which has been approved by the Food and Drug Administration (FDA) for use in drug delivery systems [12-14]. PLGA based nanoparticles are mainly produced by the double-emulsion, solvent evaporation or the spray drying techniques [15].

Since PLGA particles are hydrophobic in nature, the body recognizes them as foreign particles and eliminates them from the blood stream through the reticulo-endothelial system. This is probably one of the greatest disadvantages of particle-based controlled drug delivery systems [16] since long circulation times is key to optimised therapeutic outcomes for some drugs [17]. Researchers have attempted to overcome this limitation by modifying the surface properties of PLGA nanoparticles. This was achieved by coating with molecules that hide the hydrophobic nature of these nanoparticles by providing a hydrophilic layer at the surface and thereby increasing the blood circulation half-life of PLGA nanoparticles pronouncedly [18]. The most commonly used compounds for coating of PLGA micro- and nanoparticles are polyethylene glycol [19] and chitosan [20]. Although PLGA nanoparticle surface modification is done to improve its formulation properties [15], uncoated PLGA nanoparticles have been widely investigated to obtain fundamental information [21]. PLGA nanoparticles have been extensively investigated and have demonstrated good potential as carriers for several classes of drugs such as anticancer agents, antihypertensive agents, immunomodulators, hormones, nucleic acids, proteins, peptides and antibodies [22]. For purposes of oral drug delivery where prolonged blood circulation may be beneficial to the patient [23], it is important to investigate the movement of intact nanoparticles across epithelial cell monolayers and to identify the mechanisms by which these nanoparticles are taken up.

Since it is known that the interaction of nanoparticles varies from one cell line to another [24], it is impor- tant to test toxicity on the type of cells of interest. In this study, the toxicity of PLGA nanoparticles was investigated specifically in two epithelial cell lines (viz. Caco-2 and HeLa) and in a hepatic cell line (viz. HepG2). The epithelial cells were selected to represent the tissue type through which the nanoparticles are taken up after administration and the hepatic cells were selected to represent tissue from an organ to which the nanoparticles are exposed after uptake into the systemic circulation. The Caco-2 cell line originated from colorectal epithelial cells and under standard culturing conditions they spontaneously differentiate into columnar cells that resemble the characteristics of small intestinal enterocytes [25]. The Caco-2 cell line is an established in vitro model for predicting human intestinal drug permeability [26]. Both HeLa (human epithelial cells from cervical carcinoma) and HepG2 (human hepatocellular carcinoma cells) cells have been used successfully for in vitro toxicity studies [27]. Furthermore, both HeLa and HepG2 cell lines are commonly used to study three main cytotoxicity indicators (i.e Reactive oxygen species, intracellular glutathione depletion and calcein uptake) [28].

Although different in vitro methods are available to measure toxicity of compounds, the Trypan Blue exclusion method and MTS technique were utilised in this study to evaluate the toxicity effects of PLGA nanoparticles on the selected cell lines. Application of Trypan Blue dye to cells result in the selective staining of cells with compromised cell membranes. During the MTS technique, the compound 3-(4,5-dimethylthiazol-2-yl)-5-(3-carboxymethoxyphenyl)-2-(4-sulfophenyl)-2H-tetrazolium, is converted into a blue formazan dye by metabolically active mitochondria of viable cells [29-31].

The aim of this study was to determine the uptake and co-localisation of PLGA nanoparticles in the Caco-2 cell model by means of confocal laser scanning microscopy as well as to test the in vitro cytotoxicity of PLGA nanoparticles by means of Trypan Blue exclusion and MTS assays in the three selected cell lines (i.e. Caco-2, HeLa and HepG2).

\section{Experimental}

\subsection{Materials and cell cultures}

All mammalian cell cultures (i.e. Caco-2, HeLa and HepG2) were purchased from Highveld Biologicals (Pty) Ltd (Johannesburg, South Africa). The chemicals and growth media used to maintain cell growth 
were purchased from Sigma-Aldrich (St. Louis, Mo, United State of America). These materials include Dulbecco's Modified Eagle's Medium (DMEM), Fetal Bovine Serum, penicillin/streptomycin solution and trypsin/EDTA. Hanks Balanced Salt Solution (HBSS), D-glucose, 4-(2-hydroxyethyl)-1-piperazineethanesulfonic acid (HEPES).

The following materials were employed to formulate poly(D,L-lactide-co-glycolide) (PLGA) nanoparticles and were purchased from Sigma-Aldrich (St. Louis, Mo, United State of America): 50:50 PLGA $M_{\mathrm{w}}=40-75 \mathrm{kDa}$, with an inherent viscosity of $0.57 \mathrm{dL} / \mathrm{g}$ ), polyvinyl alcohol (PVA, $M_{\mathrm{w}}=13-$ $23 \mathrm{kDa} ; 87-89 \%$ hydrolyzed) ethyl acetate, Rhodamine $6 \mathrm{G}$ fluorophore and phosphate buffer saline (PBS).

Tissue culture flasks and Transwell ${ }^{\mathrm{TM}}$ permeable supports were supplied by Corning-Costar ${ }^{\circledR}$ (Corning, New York, USA), while the LysoTraker Green DNP-26 dye used in the confocal laser scanning microscopy (CLSM) study was purchased from Celtic Molecular Diagnostic (Mowbray, South Africa). For toxicity studies, Trypan Blue dye and emetine were also purchased from Sigma-Aldrich (St. Louis, Mo, United State of America). CellTiter $96^{\circledR}$ $\mathrm{AQ}_{\text {ueous }}$ Non-Radioactive Cell Proliferation Assay kit used in MTS method was purchased from Promega Corporation (Madison, United State of America).

\subsection{Formulation of poly(D,L-lactide-co- glycolide) nanoparticles}

The PLGA nanoparticles were prepared using a double emulsion solvent evaporation method as previously described [32]. In brief, $100 \mathrm{mg}$ of PLGA was dissolved in $8 \mathrm{~mL}$ ethyl acetate. For nanoparticle fluorescent labeling purposes, $1 \mathrm{mg}$ of Rhodamine $6 \mathrm{G}$ was dissolved in $2 \mathrm{~mL}$ PBS at $\mathrm{pH}$ 7.4. The PLGA and Rhodamine 6G solutions were mixed and placed in an ice bath and then homogenized at $5000 \mathrm{rpm}$ for 3 min using a high speed homogenizer (Silverson L4R, Silverson Machines Ltd, UK) to form the first oil-in-water $(\mathrm{o} / \mathrm{w})$ emulsion. This emulsion was poured into $40 \mathrm{~mL}$ of a $1 \%(\mathrm{w} / \mathrm{v})$ PVA solution, which was homogenized at $8000 \mathrm{rpm}$ for $3 \mathrm{~min}$ to form a water-in-oil-in-water $(\mathrm{w} / \mathrm{o} / \mathrm{w})$ emulsion. This emulsion was stirred overnight on a magnetic stirring plate at $500 \mathrm{rpm}$ to remove the organic solvent through evaporation under aseptic conditions. The pellet collected from the centrifugation step was placed at $-72^{\circ} \mathrm{C}$ (for a minimum period of $2 \mathrm{~h}$ ) prior to freeze drying. The particles were lyophilised using a Genesis 12, 25, 35 freeze-dryer (Virtis Co., New York, USA) for $24-48 \mathrm{~h}$ to obtain dry powder.

\subsection{Characterization of the physical properties of the PLGA nanoparticles}

The particle size, polydispersity index (PDI) as well as the zeta potential were determined by means of photon correlation spectroscopy using a Malvern Zetasizer Nano ZS apparatus (Malvern Instruments Ltd, Worcestershire, UK). A quantity of $2 \mathrm{mg}$ of the lyophilized PLGA nanoparticles was suspended in $1 \mathrm{~mL}$ of distilled water and vortexed for $2 \mathrm{~min}$ and then introduced into the cell of the Zetasizer apparatus for analysis. The analysis of the nanoparticle sample was performed at $25^{\circ} \mathrm{C}$ in triplicate. The surface morphology of the PLGA nanoparticles was analyzed using a scanning electron microscope (LEO 1525 Field Emission scanning electron microscope, Zeiss, Oberkochen, Germany).

\subsection{Caco-2 cell monolayer integrity}

Transepithelial electrical resistance (TEER) measurements have become universally established as the most convenient method to evaluate and monitor the development of confluent epithelial cell culture monolayers. TEER was measured with a Millicell ${ }^{\circledR}$-ERS meter (Microsep (Pty) Ltd, Johannesburg, SA) for 21 days until an acceptable reading has been obtained. A TEER value of $\geq 250 \Omega / \mathrm{cm}^{2}$ was used as a reference point to indicate the formation of an intact monolayer in order to perform cellular uptake studies [33, 34]. TEER measurements were also used to check if the PLGA nanoparticles did not affect the monolayer integrity during treatment. At the end of the uptake experiment, the cell monolayers were washed with PBS and culture medium (DMEM) was added to both apical and basolateral chambers and incubated in the incubator for $48 \mathrm{~h}$ and the TEER was then measured to determine recovery. The following Equations (1) and (2) were used to calculate TEER and TEER difference [\%]:

$\operatorname{TEER}[\Omega \cdot \mathrm{cm}]=\left(T_{\mathrm{wc}}-T_{\mathrm{nc}}\right) \cdot A$

where $T_{\mathrm{wc}}$ is the TEER readings across filters with cells, $T_{\mathrm{nc}}$ is the TEER readings across filters without cells and $\mathrm{A}$ is the membrane surface area. 
TEER difference $[\%]=\left(T_{\mathrm{bt}}-T_{\mathrm{at}}\right) \cdot 100$

where $T_{\mathrm{bt}}$ is the TEER readings before treatment at 21 days, $T_{\text {at }}$ is the TEER readings after treatment with PLGA nanoparticles.

\subsection{Cellular uptake and lysosomal co- localization of the PLGA nanoparticles}

Caco-2 cells at passage between 28-35 were seeded at a density of $1.5 \cdot 10^{5}$ cells $/ \mathrm{cm}^{2}$ on polycarbonatetreated filter membranes in Transwell plates (6-well plates, $0.4 \mu \mathrm{m}$ pores, $4.7 \mathrm{~cm}^{2}$ area) and monitored for at least 21 days until confluence was obtained. The culture medium $(2 \mathrm{~mL}$ in the filter and $3 \mathrm{~mL}$ in the well) was replaced at every $48 \mathrm{~h}$ during monitoring of the cell monolayers. The culture medium was decanted off from the Caco-2 cells and the cells were then washed three times with phosphate buffer saline and equilibrated for $1 \mathrm{~h}$ in the incubator with the assay medium HBSS supplemented with $10 \mathrm{mM}$ D-glucose and $10 \mathrm{mM}$ HEPES (pH 7.4).

The Caco-2 cell monolayers were treated with $100 \mu \mathrm{g} / \mathrm{mL}$ of Rhodamine 6G-labelled PLGA nanoparticles and also stained with $1 \mu \mathrm{g} / \mathrm{mL}$ of LysoTraker Green DNP-26 dye in order to visualize the compartmentalization of nanoparticles within lysosomes. The cells were incubated over a $2 \mathrm{~h}$ period and the cells were visualized with the CLSM at 0.5, 1 and $2 \mathrm{~h}$. At each time point, the medium was removed and the cells were washed with PBS to remove excess Rhodamine 6G-labelled PLGA nanoparticles. The filter membrane with attached cell monolayer was cut using a sterile blade and mounted to a microscope slide and the cover slip was put in place. The images were acquired with a filter that is appropriate for each fluorescent dye as described below.

These experiments were performed with a PCM2000 CLSM with a pinhole setting of $1 / 4$ Array Units used for optimal sample viewing. The fluorescence of LysoTraker Green DNP-26 (488 nm line of Argon Ion laser with $515 \mathrm{~nm}$ emission filter) and Rhodamine 6G (525 nm line of Helium-Neon laser with $550 \mathrm{~nm}$ emission filter) was monitored in different optical sections. Z-series of optical sections were acquired at spacing steps of $0.6 \mu \mathrm{m}$ from the surface through the vertical axis of the specimen by a computer-controlled motor drive. Images were captured with EZ2000 Software and converted to Tag Image File Format.

\subsection{Cytotoxicity of PLGA nanoparticles 2.6.1. Trypan blue exclusion}

Caco-2, HeLa and HepG2 cells were seeded in $100 \mathrm{~mm}$ tissue culture dishes at a density of $1 \cdot 10^{5} \mathrm{cell} / \mathrm{s} / \mathrm{cm}^{2}$ and grown for $24 \mathrm{~h}$ in DMEM. The cells were washed three times with PBS and treated with $1.2 \mathrm{mg} / \mathrm{mL}$ of PLGA nanoparticles for $24 \mathrm{~h}$. As a control, selected dishes containing cells from each cell line were not treated with nanoparticles. After the $24 \mathrm{~h}$ period, the cells were detached from the surface area with $1 \mathrm{~mL}$ trypsin/EDTA and neutralized with DMEM. Stained cells (i.e. non-viable cells) and non-stained cells (i.e. viable cells) were counted with a haemocytometer under an inverted microscope (Axiovert, Zeiss) to calculate the percentage viability of the cells.

\subsubsection{MTS assay}

Caco- 2 cells were seeded in 96-well plates in $100 \mu \mathrm{L}$ of culture medium at a density of $1 \cdot 10^{4}$ cells/well and grown for $24 \mathrm{~h}$ in culturing medium. The Caco-2 cells were then washed three times with PBS. The cells were then treated with $100 \mu \mathrm{L}$ of PLGA nanoparticles suspensions prepared in DMEM with the following concentrations: $0.01,0.07,0.64$ and $5.8 \mathrm{mg} / \mathrm{mL}$. The positive control group consisted of emetine solutions with the following concentrations: $0.01,0.07,0.64$ and $5.8 \mu \mathrm{g} / \mathrm{mL}$. The plate was then incubated at $37^{\circ} \mathrm{C}, 5 \% \mathrm{CO}_{2}$ and $90 \%$ humidity conditions for $24 \mathrm{~h}$ after which $20 \mu \mathrm{L}$ of a mixture of MTS-based solution were added directly into each well. The plate was then incubated for additional $3 \mathrm{~h}$ under same atmospheric conditions and the absorbance measured at $490 \mathrm{~nm}$ in a spectrophotometric microtitre plate reader (Tecan Infinite F500, Männedorf, Switzerland) against blank wells (with only DMEM) to subtract background absorbance at $690 \mathrm{~nm}$. Cells incubated with DMEM without PLGA nanoparticles were used as a negative control. The cell viability was expressed as a percentage relative to the control as calculated by Equation (3):

Cell viability [\%] $=\frac{O D_{\text {sample }}}{O D_{\text {control }}}$

where $O D_{\text {sample }}$ is the optical density of the test compound, $O D_{\text {control }}$ is the optical density of the control group (untreated cells). 


\subsection{Data analysis and statistics}

All results reported in this article are expressed as mean \pm standard deviation (SD) of three replicates $(n=3)$, unless otherwise stated. Statistical evaluation was performed with Student's $t$ test using Microsoft Office Excel (2007) merged with GraphPad Prism 4.0 (2008) (Microsoft Corporation, Redmond, Washington, USA). A probability ( $p$ ) value of less than or equal to 0.05 was considered statistically significant.

\section{Results and discussion}

\subsection{Physical properties of the PLGA nanoparticles}

The Rhodamine 6G-labelled PLGA nanoparticles had an average size of $266.8 \pm 10.5 \mathrm{~nm}$ with a PDI value of $0.061 \pm 0.005$, indicating a relatively narrow particle size distribution. The zeta potential of Rhodamine 6G-labelled PLGA nanoparticles was found to be $-16.1 \pm 1.7 \mathrm{mV}$.

\subsection{Caco-2 cell monolayer integrity}

The TEER values of the Caco- 2 cell monolayers increased steadily over time under normal culturing conditions until values above $250 \Omega \cdot \mathrm{cm}^{2}$ were reached. This indicated that intact cell monolayers with well-developed tight junctions were formed. The decrease in TEER after treatment of the cell monolayers with PLGA nanoparticles was below $10 \%$, which indicated that treatment with the PLGA

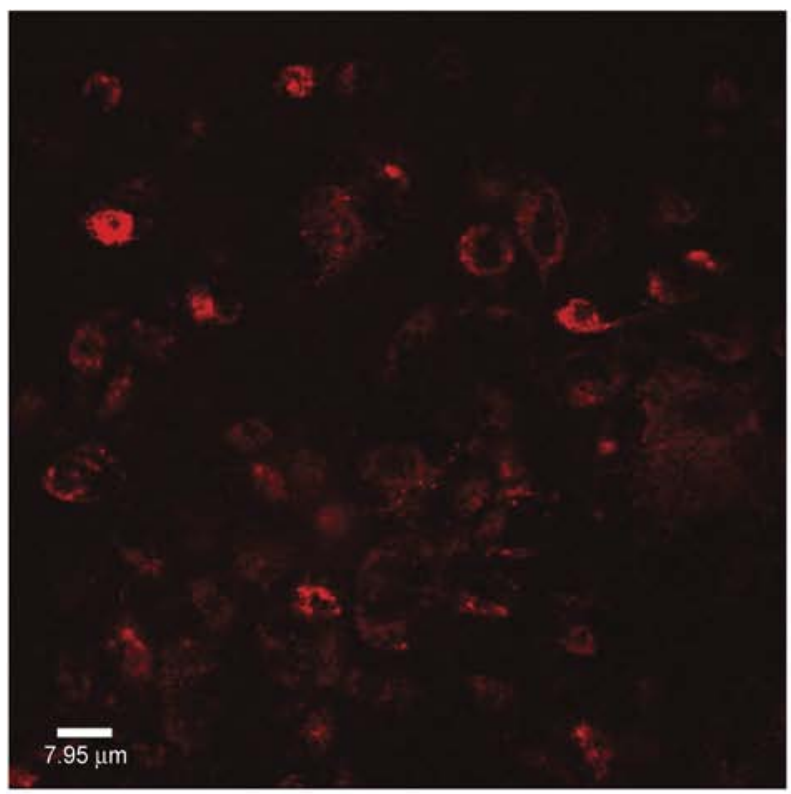

a)

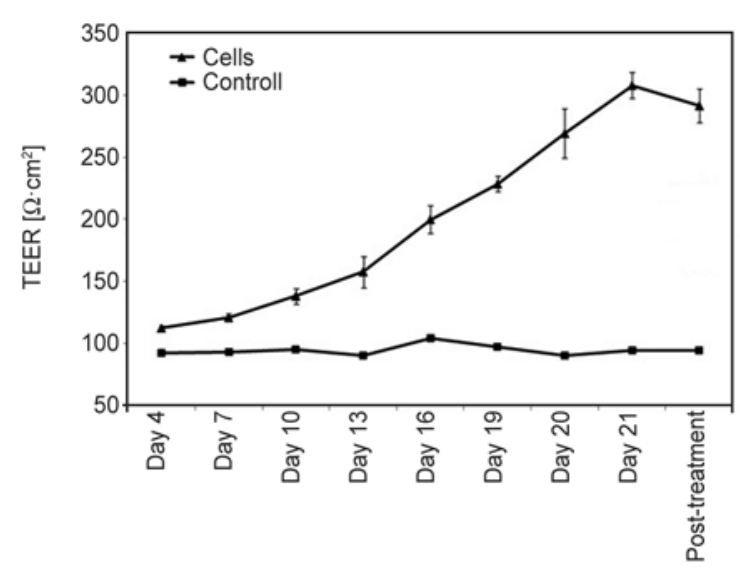

Figure 1. Transepithelial electrical resistance across the Caco-2 monolayers grown on a filter membrane as a function of culture time as well as before and after treatment compared to the control (filter membranes without cells)

nanoparticles did not compromise the cell monolayer integrity (Figure 1).

\subsection{Cellular uptake of PLGA nanoparticles}

Confocal laser scanning microscopy (CLSM) images presented in Figure 2 clearly indicate that the Rhodamine 6G-labeleld PLGA nanoparticles were internalized and accumulated within the Caco- 2 cells in a time-dependent way. The Rhodamine 6G-labeleld PLGA nanoparticles were taken up to a lower extend after 30 min of incubation (Figure 2a) compared to 90 min incubation time (Figure 2b) as indicated by

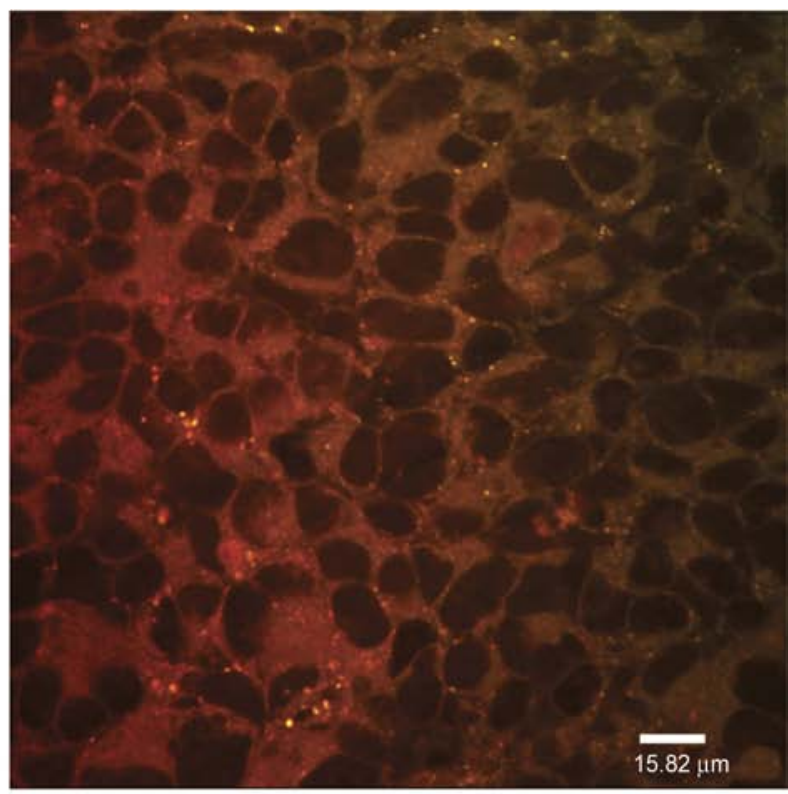

b)

Figure 2. Confocal laser scanning microscopy images of Caco-2 cell monolayers treated with Rhodamine 6G-labelled PLGA nanoparticles after $30 \mathrm{~min}$ (a) and $90 \mathrm{~min}$ (b), respectively 
the number of fluorescent dots in the cells. Figure $2 \mathrm{~b}$ also indicates that accumulation of the Rhodamine 6G-labelled PLGA nanoparticles not only occurred within the Caco-2 cells, but they also accumulated in the intercellular spaces between the cells after $90 \mathrm{~min}$ of exposure time.

The fact that the PLGA nanoparticles have been internalized within the Caco-2 cells is in line with previous findings that indicated intact nanoparticles could gain access to the intracellular milieu of epithelial cells and could even move into cytoplasmic organelles [35].

\subsection{Lysosomal co-localization of PLGA nanoparticles}

Figure 3a shows a CLSM image of Rhodamine 6Glabelled PLGA nanoparticles taken up by a single Caco- 2 cell (red fluorescing color) after $60 \mathrm{~min}$ incubation time, while the image in Figure $3 b$ illustrates LysoTraker Green dye within the lysosomes (green fluorescing color) of the same cell. Figure $3 \mathrm{c}$ shows that the PLGA nanoparticles were co-loclize within some of the lysosomes of the cell as indicated by the yellowish fluorescence (some of which are pointed out by arrows on the image), which is a combination of both red and green fluorescence. This indicates that a portion of the PLGA nanoparticles were taken up by means of endocytosis and thereby co-localized within the lysosomes. The endocytosis pathway is the only uptake mechanism by which intracellular lysosomal/phagosomal co-localization of particles can be justified [36, 37]. Lysosomes are organelles that contain degradation enzymes which digest foreign particles [38], but a specialized endocytotic process (i.e. transcytosis) can escape endolysosomal degradation [39]. It was further confirmed in an in vitro study that nanoparticles taken up by means of transcytosis escaped lysosomal degradation to be released into the systemic circulation [40].

\subsection{Cellular internalization of PLGA nanoparticles}

In order to confirm that the PLGA nanoparticles were taken up into the Caco- 2 cells and not only adsorbed onto the surface of the cell membrane, their uptake was quantified by acquiring and evaluating slices of the cell monolayer that was stacked together with cross-sectional slices perpendicular to the plane of the cell monolayer midpoint ( $z$-axis). The $z$-direction image (Figure 4) shows that the Rhodamine 6Glabelled PLGA nanoparticles were taken up crosssectional and when viewed from the side it is clear that they got transported from the apical surface of the cell membrane towards the basolateral membrane. The $z$-slices further show that PLGA nanoparticles were present in different planes throughout the thickness of the monolayer. This confirms transcellular uptake of the PLGA nanoparticles by intestinal epithelial cell monolayers and co-localisation in lysosomes (yellow fluorescence as indicated with arrows in Figure 3). In a previous study [41], localisation of PLGA nanoparticles was demonstrated within organelles such as the cell nucleus for particles in the $100 \mathrm{~nm}$ size range, whereas in this study the PLGA nanoparticles (with size of $266.8 \mathrm{~nm}$ ) were found to be co-localised within the lysosomes. It is important to mention nanoparticle size and size distribution patterns are factors that may influence their interaction with the cell membrane [22]. Studies previously conducted on nanoparticles with an average size between 200 and $350 \mathrm{~nm}$ found that they were distributed to various tissues [32], while nano-

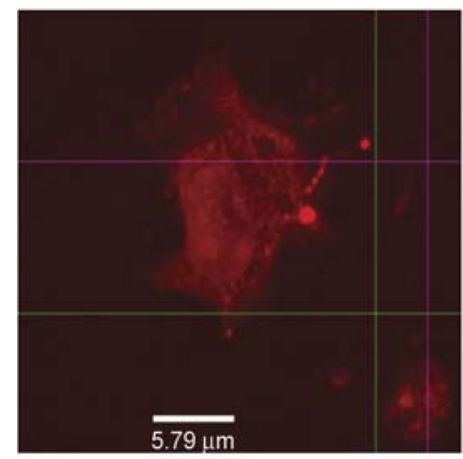

a)

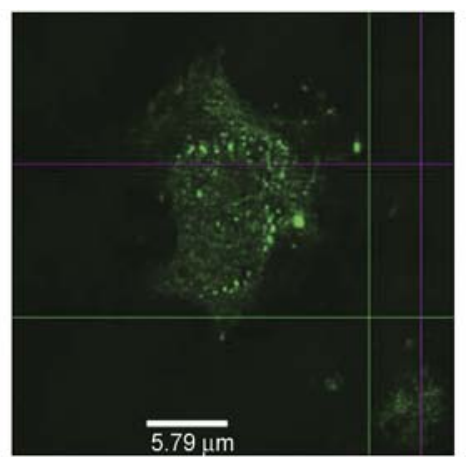

b)

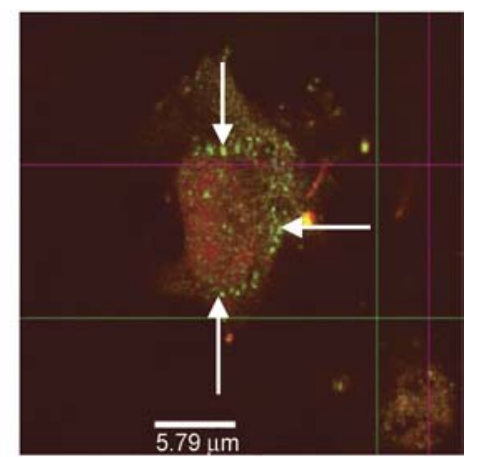

c)

Figure 3. Confocal laser scanning microscopy images of a single Caco-2 cell exposed to Rhodamine 6G-labelled PLGA particles for 60 min. a) PLGA nanoparticles (red) taken up by the Caco-2 cell, b) compartmentalisation of green fluorescence from Lysotracker green within lysosomes in the Caco-2 cell and c) co-localisation of PLGA nanoparticles (yellowish green) within the lysosomes (indicated by arrows) 


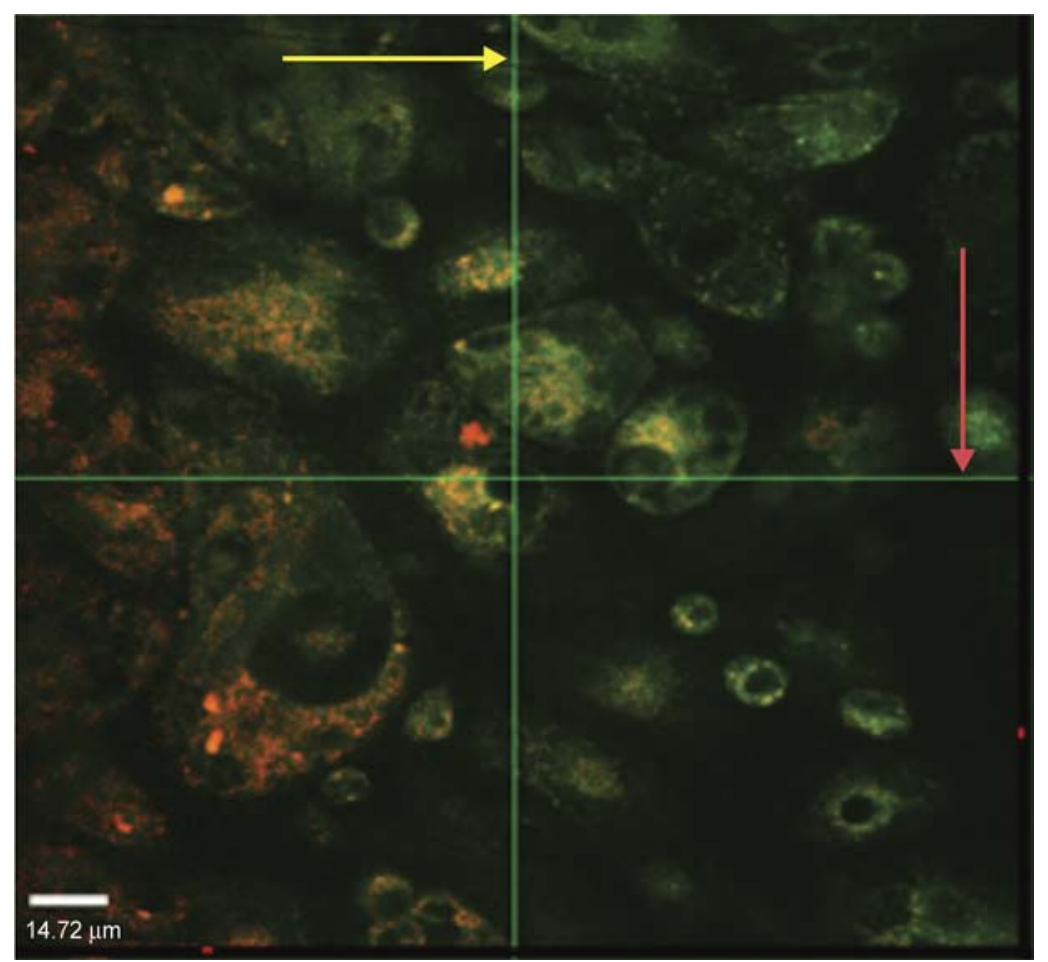

Figure 4. Z-stack images of Caco-2 cells 90 min after exposure to Rhodamine 6G-labelled PLGA nanoparticles. Images sectioned vertical (orange arrow) and parallel (red arrow) indicating cell adsorption of nanoparticles within cell monolayers

particles smaller than $70 \mathrm{~nm}$ was rapidly excreted by the kidneys. Surface charge or zeta potential of nanoparticles was also shown to be an important factor that may influence cellular internalization of nanoparticles, especially when they are oppositely charged than the cell's membrane [42].

\subsection{Cytotoxicity of PLGA nanoparticles 3.6.1. Trypan blue exclusion and MTS assay}

The viability of the different cell lines according to the Trypan blue exclusion test after exposure to PLGA nanoparticles is shown in Figure 5. There was no significant difference observed in the percentage cell viability for all three cell types $(p=0.95$ for Caco-2; $p=0.91$ for HepG2 and $p=0.63$ for HeLa cells) between untreated cells (negative control) and those that were treated with PLGA nanoparticles at a concentration of $1.2 \mathrm{mg} / \mathrm{mL}$. The trypan blue exclusion study therefore indicated that the PLGA nanoparticles were not cytotoxic to mammalian cell lines investigated. The MTS assay results confirmed that PLGA nanoparticles were not toxic to Caco-2 cells even when treated to a maximum concentration of $5.8 \mathrm{mg} / \mathrm{mL}$ (Figure 6) in comparison to emetine, which shown a markedly decrease in cell viability with increasing concentration (Figure 7). Team work previously conducted on similar PLGA nano-

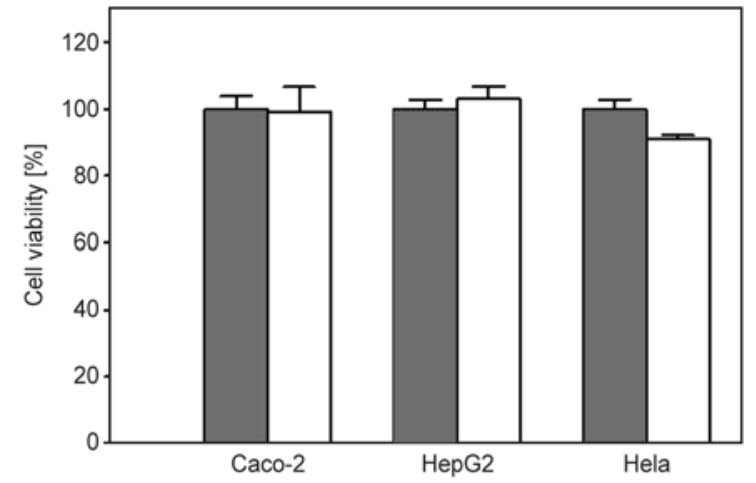

Figure 5. Viability of different mammalian cell lines determined by means of the Trypan blue exclusion test. (घ) represents untreated cells (control) and ( $\square$ ) represents cells treated with PLGA nanoparticles. Data presented as mean $\pm \mathrm{SD}, n=3$

particles used in this study showed that PLGA nanoparticles with an average size of $300 \mathrm{~nm}$ had no detrimental effects on mammalian cells including Caco-2 cells up to a concentration range of $0.001 \mathrm{mg} / \mathrm{mL}$ [32]. Particles prepared by the emulsion solvent evaporation technique were not toxic to human glioblastoma U87MG cells at $200 \mu \mathrm{g} / \mathrm{mL}$ [43] or mammalian cells $[44,45]$. This study showed that PLGA nanoparticles are not toxic to Caco-2 cells even at relatively high concentrations, which have not been evaluated before. Emetine was used as the positive control (due to its toxicity on eukaryotic cells by 


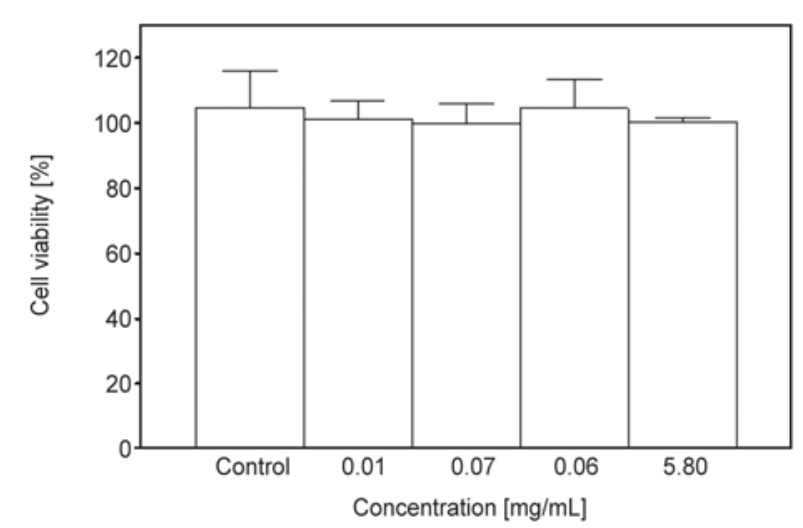

Figure 6. Viability of Caco-2 cells expressed relative to the control (not treated), which exposed to different concentrations of PLGA nanoparticles as determined by the MTS assay. Data presented as mean $\pm \mathrm{SD}, n=3$

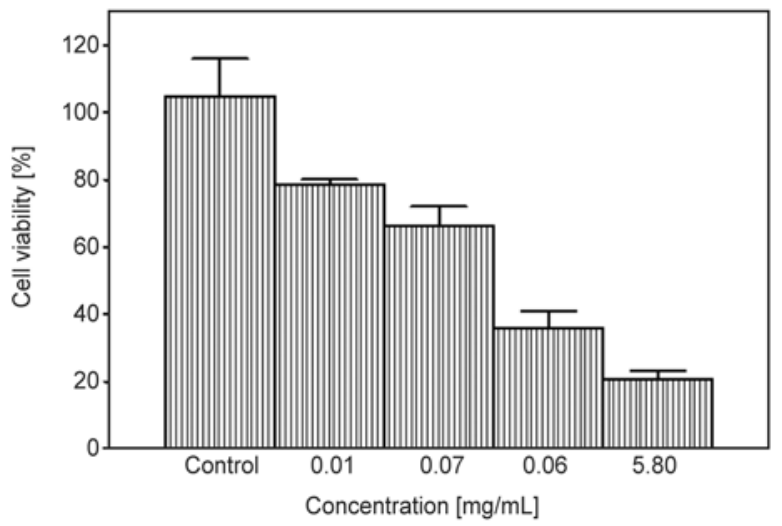

Figure 7. Viability of Caco-2 cells expressed relative to the control (not treated), which were exposed to various concentrations of emetine as determined by the MTS method. Data presented as mean $\pm \mathrm{SD}$, $n=3$

blocking protein synthesis [46] and showed a toxic effect on the Caco-2 cells investigated in this study.

\section{Conclusions}

From the confocal laser scanning microscopy results it can be concluded that the PLGA nanoparticles accumulated to some extent in the intercellular spaces of Caco-2 cell monolayers which indicated paracellular movement of the nanoparticles across the epithelium. However, the PLGA nanoparticles were also clearly taken up by the transcellular pathway into the Caco-2 cells which indicated simultaneous transcellular movement. This transcellular uptake of the PLGA nanoparticles occurred partially through endocytosis as indicated by co-localisation in the lysosomes. Furthermore, PLGA nanoparticles were non-cytotoxic to three different mammalian cell lines, which confirm their safe use as drug carrier systems. Since it was shown in this study that intact PLGA nanoparticles move across epithelial cell monolayers without damaging these cells, they are suitable as drug carrier systems specifically for applications such as targeting specific tissues or to prolong blood circulation time after oral administration. It is recommended that future studies investigate the influence of physiological factors as well as physical properties of the nanoparticles on their mechanism of uptake in epithelial cells.

\section{Acknowledgements}

This study was supported in part by a grant-in-aid for Scientific Research (No. DMLIB-\#49779-v2-MOA) from the Department of Science and Technology (DST) of South Africa. Also, gratitude expressed to CSIR Biosciences, for studentship financial support.

\section{References}

[1] Khuller G. K., Kapur M., Sharma S.: Liposome technology for drug delivery against mycobacterial infections. Current Pharmaceutical Design, 10, 3263-3274 (2004).

DOI: $10.2174 / 1381612043383250$

[2] Li X., Chen D., Le C., Zhu C., Gan Y., Hovgaard L., Yang M.: Novel mucus-penetrating liposomes as a potential oral drug delivery system: Preparation, in vitro characterization, and enhanced cellular uptake. International Journal of Nanomedicine, 6, 3151-3162 (2011). DOI: $10.2147 /$ IJN.S25741

[3] Bob I.: Nanoparticle drug delivery systems. Innovation in Pharmaceutical Biotechnology, 24, 58-62 (2007).

[4] Fattal E., Pecquet S., Couvreur P., Andremont A.: Biodegradable microparticles for the mucosal delivery of antibacterial and dietary antigens. International Journal of Pharmaceutics, 242, 15-24 (2002). DOI: $10.1016 / \mathrm{S} 0378-5173(02) 00181-3$

[5] Desai M. P., Labhasetwar V., Walter E., Levy R. J., Amidon G. L.: The mechanism of uptake of biodegradable microparticles in Caco- 2 cells is size dependent. Pharmaceutical Research, 14, 1568-1573 (1997). DOI: $10.1023 / \mathrm{A}: 1012126301290$

[6] Martinho N., Damgé C., Reis C. P.: Recent advances in drug delivery systems. Journal of Biomaterials and Nanobiotechnology, 2, 510-526 (2011). DOI: $10.4236 /$ jbnb.2011.225062

[7] Anderson J. M., Shive M. S.: Biodegradation and biocompatibility of PLA and PLGA microspheres. Advanced Drug Delivery Review, 28, 5-24 (1997). DOI: 10.1016/S0169-409X(97)00048-3

[8] Nair L. S., Laurencin C. T.: Biodegradable polymers as biomaterials. Progress in Polymer Science, 32, 762 798 (2007). DOI: 10.1016/j.progpolymsci.2007.05.017 
[9] Makadia H. K., Siegel S. J.: Poly lactic-co-glycolic acid (PLGA) as biodegradable controlled drug delivery carrier. Polymers, 3, 1377-1397 (2011).

DOI: $10.3390 /$ polym 3031377

[10] Jain R. A.: The manufacturing techniques of various drug loaded biodegradable poly(lactide-co-glycolide) (PLGA) devices. Biomaterials, 21, 2475-2490 (2000). DOI: $10.1016 / \mathrm{S} 0142-9612(00) 00115-0$

[11] Athanasiou K. A., Niederauer G. G., Agrawal C. M.: Sterilization, toxicity, biocompatibility and clinical applications of polylactic acid/polyglycolic acid copolymers. Biomaterials, 17, 93-102 (1996).

DOI: 10.1016/0142-9612(96)85754-1

[12] Chakravarthi S. S., Robinson D. H., De S.: Nanoparticulate drug delivery systems. in 'Nanoparticles prepared using natural and synthetic polymers' (eds.: Thassu D., Deleers M., Pathak Y.) Informa Healthcare, New York, 51-60 (2007).

[13] Lewis D. H.: Controlled release of bioactive agents from lactide/glycolide polymers. in 'Biodegradable polymers as drug delivery systems' (eds.: Chasin M., Langer R.) Marcel Dekker, New York, 1-41 (1990).

[14] Ishihara T., Kubota T., Choi T., Takahashi M., Ayano E., Kanazawa H., Higaki M.: Polymeric nanoparticles encapsulating betamethasone phosphate with different release profiles and stealthiness. International Journal of Pharmaceutics, 375, 148-154 (2009).

DOI: $10.1016 /$ j.ijpharm.2009.04.001

[15] Mundargi R. C., Babu V. R., Rangaswamy V., Patel P., Aminabhavi T. M.: Nano/micro technologies for delivering macromolecular therapeutics using poly(D,Llactide-co-glycolide) and its derivatives. Journal of Controlled Release, 125, 193-209 (2008).

DOI: 10.1016/j.jconrel.2007.09.013

[16] Kumari A., Yadav S. K., Yadav S. C.: Biodegradable polymeric nanoparticles based drug delivery systems. Colloids and Surfaces B: Biointerfaces, 75, 1-18 (2010). DOI: 10.1016/j.colsurfb.2009.09.001

[17] Soppimath K. S., Aminabhavi T. M., Kulkarni A. R., Rudzinski W. E.: Biodegradable polymeric nanoparticles as drug delivery devices. Journal of Controlled Release, 70, 1-20 (2001).

DOI: $10.1016 / \mathrm{S} 0168-3659(00) 00339-4$

[18] Owens D. E., Peppas N. A.: Opsonization, biodistribution, and pharmacokinetics of polymeric nanoparticles. International Journal of Pharmaceutics, 307, 93102 (2006).

DOI: $10.1016 /$ j.ijpharm.2005.10.010

[19] Danhier F., Feron O., Préat V.: To exploit the tumor microenvironment: Passive and active tumor targeting of nanocarriers for anti-cancer drug delivery. Journal of Controlled Release, 148, 135-146 (2010). DOI: $10.1016 /$ j.jconrel.2010.08.027
[20] Tahara K., Sakai T., Yamamoto H., Takeuchi H., Hirashima N., Kawashima Y.: Improved cellular uptake of chitosan-modified PLGA nanospheres by A549 cells. International Journal of Pharmaceutics, 382, 198-204 (2009).

DOI: 10.1016/j.ijpharm.2009.07.023

[21] Shenoy D. B., Amiji M. M.: Poly(ethylene oxide)modified poly( $\varepsilon$-caprolactone) nanoparticles for targeted delivery of tamoxifen in breast cancer. International Journal of Pharmaceutics, 293, 261-270 (2005). DOI: 10.1016/j.ijpharm.2004.12.010

[22] Danhier F., Ansorena E., Silva J. M., Coco R., Le Breton A., Préat V.: PLGA-based nanoparticles: An overview of biomedical applications. Journal of Controlled Release, 161, 505-522 (2012).

DOI: $10.1016 /$ j.jconrel.2012.01.043

[23] Letendre L., Scott M., Dobson G., Hidalgo I., Aungst B.: Evaluating barriers to bioavailability in vivo: Validation of a technique for separately assessing gastrointestinal absorption and hepatic extraction. Pharmaceutical Research, 21, 1457-1462 (2004). DOI: 10.1023/B:PHAM.0000036921.87928.72

[24] Vasir J. K., Labhasetwar V.: Quantification of the force of nanoparticle-cell membrane interactions and its influence on intracellular trafficking of nanoparticles. Biomaterials, 29, 4244-4252 (2008). DOI: 10.1016/j.biomaterials.2008.07.020

[25] Hidalgo I. J., Raub T. J., Borchardt R. T.: Characterization of the human colon carcinoma cell line (Caco-2) as a model system for intestinal epithelial permeability. Gastroenterology, 96, 736-749 (1989).

[26] Li A. P.: Screening for human ADME/Tox drug properties in drug discovery. Drug Discovery Today, 6, 357-366 (2001). DOI: $10.1016 / \mathrm{S} 1359-6446(01) 01712-3$

[27] du Plessis L. H., Hamman J. H.: In vitro evaluation of the cytotoxic and apoptogenic properties of aloe whole leaf and gel materials. Drug and Chemical Toxicology, in press, p.9 (2013). DOI: $10.3109 / 01480545.2013 .834356$

[28] Schoonen W. G. E. J., Westerink W. M. A., de Roos J. A. D. M., Débiton E.: Cytotoxic effects of 100 reference compounds on Hep G2 and HeLa cells and of 60 compounds on ECC-1 and CHO cells. I Mechanistic assays on ROS, glutathione depletion and calcein uptake. Toxicology in Vitro, 19, 505-516 (2005). DOI: $10.1016 /$ j.tiv.2005.01.003

[29] Mosmann T.: Rapid colorimetric assay for cellular growth and survival: Application to proliferation and cytotoxicity assays. Journal of Immunological Methods, 65, 55-63 (1983). DOI: 10.1016/0022-1759(83)90303-4

[30] Vistica D. T., Skehan P., Scudiero D., Monks A., Pittman A., Boyd M. R.: Tetrazolium based assay for cellular viability: A critical examination of selected parameters affecting formazan production. Cancer Research, 51, 2515-2520 (1991). 
[31] Wrobel K., Claudio E., Segade F., Ramos S., Lazo K.: Measurement of cytotoxicity by propidium iodide staining of target cell DNA: Application to the quantification of murine TNF- $\alpha$. Journal of Immunological Methods, 189, 243-249 (1996).

DOI: 10.1016/0022-1759(95)00253-7

[32] Semete B., Booysen L., Lemmer Y., Kalombo L., Katata L., Verschoor J., Swai H. S.: In vivo evaluation of the biodistribution and safety of PLGA nanoparticles as drug delivery systems. Nanomedicine: Nanotechnology, Biology and Medicine, 6, 662-671 (2010). DOI: $10.1016 /$ j.nano.2010.02.002

[33] Artursson P., Palm K., Luthman K.: Caco-2 monolayers in experimental and theoretical predictions of drug transport. Advanced Drug Delivery Reviews, 46, 27 43 (2001). DOI: $10.1016 / \mathrm{S} 0169-409 X(00) 00128-9$

[34] Hubatsch I., Ragnarsson E. E. G., Artursson P.: Determination of drug permeability and prediction of drug absorption in Caco-2 monolayers. Nature Protocols, 2, 2111-2119 (2007).

DOI: $10.1038 /$ nprot.2007.303

[35] Qaddoumi M. G., Ueda H., Yang J., Davda J., Labhasetwar V., Lee V. H.: The characteristics and mechanisms of uptake of PLGA nanoparticles in rabbit conjunctival epithelial cell layers. Pharmaceutical Research, 21, 641-648 (2004). DOI: 10.1023/B:PHAM.0000022411.47059.76

[36] Panyam J., Labhasetwar V.: Targeting intracellular targets. Current Drug Delivery, 1, 235-247 (2004). DOI: $10.2174 / 1567201043334768$

[37] Cartiera M. S., Ferreira E. C., Caputo C., Egan M. E., Caplan M. J., Saltzman W. M.: Partial correction of cystic fibrosis defects with PLGA nanoparticles encapsulating curcumin. Molecular Pharmaceutics, 7, 86-93 (2009).

DOI: $10.1021 / \mathrm{mp} 900138 \mathrm{a}$

[38] Ayala P., Lin L., Hopper S., Fukuda M., So M.: Infection of epithelial cells by pathogenic neisseriae reduces the levels of multiple lysosomal constituents. Infection and Immunity, 66, 5001-5007 (1998).
[39] Panyam J., Zhou W-Z., Prabha S., Sahoo S. K., Labhasetwar V.: Rapid endo-lysosomal escape of poly(DLlactide-co-glycolide) nanoparticles: Implications for drug and gene delivery. The FASEB Journal, 16, 12171226 (2002). DOI: 10.1096/fj.02-0088com

[40] Sanderson I. R., Walker W. A.: Uptake and transport of macromolecules by the intestine: Possible role in clinical disorder (an update). Gastroenterology, 104, 622629 (1993).

[41] Gaumet M., Gurny R., Delie F.: Localization and quantification of biodegradable particles in an intestinal cell model: The influence of particle size. European Journal of Pharmaceutical Sciences, 36, 465-473 (2009). DOI: $10.1016 /$ j.ejps.2008.11.015

[42] He C., Hu Y., Yin L., Tang C., Yin C.: Effects of particle size and surface charge on cellular uptake and biodistribution of polymeric nanoparticles. Biomaterials, 31, 3657-3666 (2010).

DOI: $10.1016 /$ j.biomaterials.2010.01.065

[43] Mo L., Hou L., Guo D., Xiao X., Mao P., Yang X.: Preparation and characterization of teniposide PLGA nanoparticles and their uptake in human glioblastoma U87MG cells. International Journal of Pharmaceutics, 436, 815-824 (2012). DOI: 10.1016/j.ijpharm.2012.07.050

[44] Csaba N., Caamaño P., Sanchez A., Domınguez F., Alonso M. J.: PLGA:Poloxamer and PLGA:Poloxamine blend nanoparticles: New carriers for gene delivery. Biomacromolecules, 6, 271-278 (2005).

DOI: $10.1021 / \mathrm{bm} 049577 \mathrm{p}$

[45] Mura S., Hillaireau H., Nicolas J., Le Droumaguet B., Gueutin C., Zanna S., Tsapis N., Fattal E.: Influence of surface charge on the potential toxicity of PLGA nanoparticles towards Calu-3 cells. International Journal of Nanomedicine, 6, 2591-2605 (2011).

DOI: $10.2147 /$ IJN.S24552

[46] Dimitrijevic S., Duncan R.: Synthesis and characterization of N-(2-Hydroxypropyl)-methacrylamide (HPMA) copolymer-emetine conjugates. Journal of Bioactive and Compatible Polymers, 13, 165-178 (1998). DOI: $10.1177 / 088391159801300301$ 